\title{
East Asian Monsoon and paleoclimatic data analysis: a vegetation point of view
}

\author{
J. Guiot ${ }^{1}$, Hai Bin $\mathrm{Wu}^{2,3}$, Wen Ying Jiang ${ }^{4}$, and Yun Li Luo ${ }^{5}$ \\ ${ }^{1}$ CEREGE, CNRS/Université Paul Cézanne UMR 6635, BP 80, 13545 Aix-en-Provence cedex France \\ ${ }^{2}$ SKLL, Institute of Earth Environment, Chinese Academy of Sciences, Xian 710075, China \\ ${ }^{3}$ Institut des Sciences de l'Environnement, UQAM, Montreal PQ, H3C 3P8 Canada \\ ${ }^{4}$ Key Laboratory of Cenozoic Geology and Environment, Institute of Geology and Geophysics, Chinese Academy of \\ Sciences, 100029 Beijing, China \\ ${ }^{5}$ Institute of Botany, Chinese Academy of Sciences, 100093, Beijing, China
}

Received: 10 December 2007 - Published in Clim. Past Discuss.: 20 February 2008

Revised: 27 May 2008 - Accepted: 11 June 2008 - Published: 26 June 2008

\begin{abstract}
First we review several syntheses of paleodata (pollen, lake-levels) showing the climate variations in China and Mongolia from the last glacial maximum to Present and in particular the precipitation increase at mid Holocene related to enhanced monsoon. All these results concur to a much enhanced monsoon on most of China during the first half of the Holocene. Second we present, in some details, a temporal study of a core (Lake Bayanchagan, Inner Mongolia) located in an arid region at the edge of the present East Asian Monsoon (EAM) influence and then sensitive to climatic change. This study involves pollen data together with other macro-remains and stable isotope curve to obtain a robust climate reconstruction. This study shows a long wet period between 11000 and 5000 years BP divided in two parts, a warmer one from 11000 and 8000 (marked by large evapotranspiration) and a cooler one more favourable to forest expansion. Third, we present a spatial study based on pollen data only and covering all China and Mongolia at 6000 years $\mathrm{BP}$, but using a mechanistic modelling approach, in an inverse mode. It has the advantage to take into account environmental context different from the present one (lower atmospheric $\mathrm{CO}_{2}$, different seasonality). This study shows temperature generally cooler than present one in southern China, but a significant warming was found over Mongolia, and a slightly higher in northeast China. Precipitation was generally higher than today in southern, northeast China, and northern Mongolia, but lower or similar to today in northwest China and north China. Enhanced EAM was then found in the southern half of China and in northeast China.
\end{abstract}

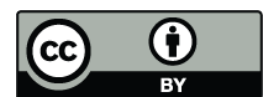

Correspondence to: J. Guiot (guiot@cerege.fr)

\section{Introduction}

The past 21000 years are a very interesting time period period as it contains two extreme states of the climate. The Last Glacial maximum (LGM, 21000 years BP) is a cold and generally dry period driven by enlarged ice sheets and low atmospheric $\mathrm{CO}_{2}$. The mid-Holocene period (6000 years BP), generally warmer and wetter than the present one, is considered as orbital forced period with perihelion in northern summer/autumn and greater-than-present axial tilt (Berger, 1978) but free of major ice-sheet and relatively high $\mathrm{CO}_{2}$ (taking as reference the pre-industrial present time). These two periods have been chosen as key time periods by the Palaeoclimate Modelling Intercompraison Project, PMIP (Joussaume and Taylor, 1995). The mid-Holocene, with its high summer insolation, is a period of high land-sea contrast and consequently enhanced monsoon (Braconnot et al., 2002). It is of particular interest for climate modellers to test their simulations through palaeodata from the monsoonal regions.

The East Asian monsoon (EAM) is one of the most active components of the global climate system, influencing a large area of China and its surrounding countries. In China and surrounding countries, a megathermal period was reconstructed from 9500 to $4000 \mathrm{yr}$ ago (Shi et al., 1993). However, many recent studies have shown that Holocene climatic changes were asynchronous across China (An, 2000; An et al., 2006; He et al., 2004). The Holocene optimum was defined as EAM precipitation maximum, occurring ca. $11000-$ $9000 \mathrm{yr}$ ago in northeastern China, $11000-8000 \mathrm{yr}$ ago in north-central and northern east-central China, 8000-6000 yr ago in central China, and ca. $3500 \mathrm{yr}$ ago in southern China (An, 2000). The reason for debate on Holocene climatic variations is that complexity of the EAM, and different responses of environmental proxies to climatic changes (Wei and Gasse, 1999; Wang et al., 2003). Therefore, more

Published by Copernicus Publications on behalf of the European Geosciences Union. 


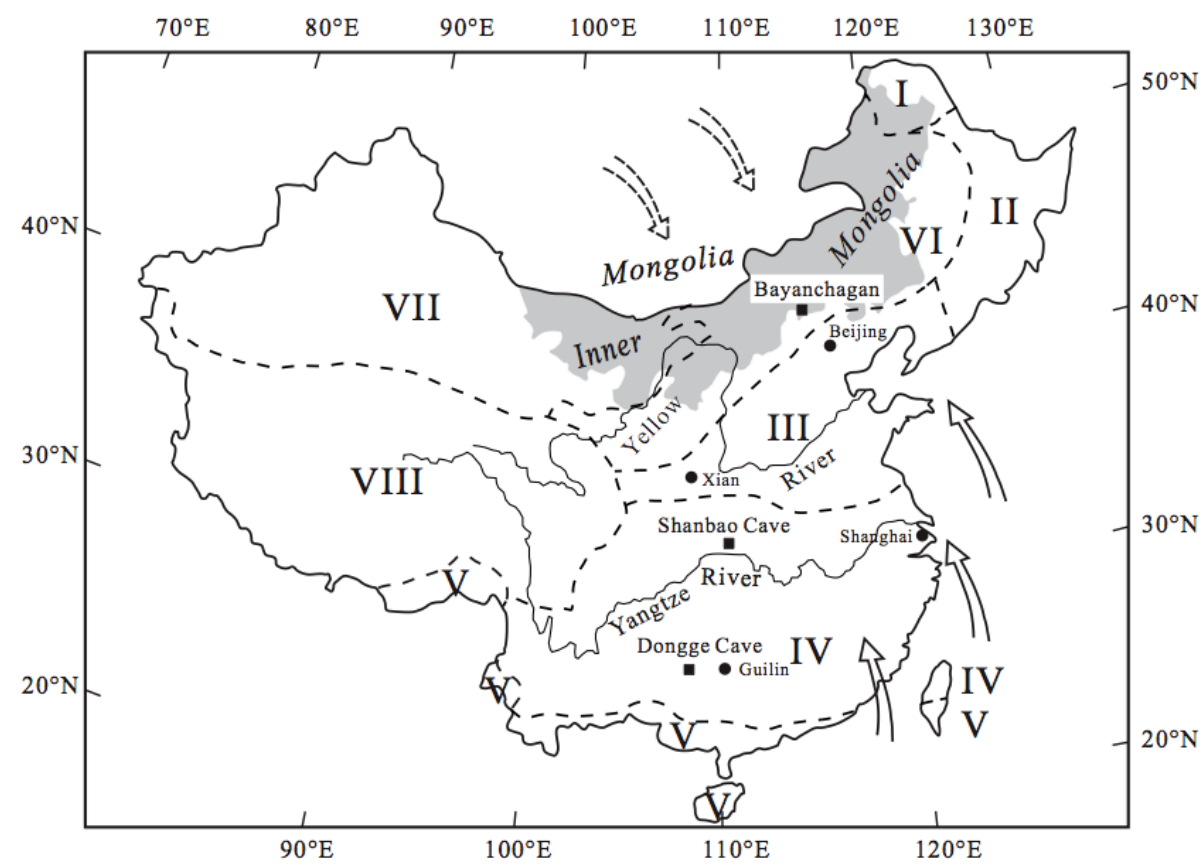

Fig. 1. Location of studied site and modern vegetation zones in China (after Jiang et al., 2006). I, Cold-temperate conifer forest; II, Temperate mixed conifer-broadleaved forest; III, Warm-temperate broadleaved deciduous forest; IV, Subtropical evergreen broadleaved forest; V, Tropical rainforest and seasonal rainforest; VI, Steppe; VII, Desert; VIII, Tibet-Qinghai cold and highland vegetation. The dashed and solid arrows indicate winter monsoon and the dominant direction of the summer monsoon precipitation belt, respectively.

precisely dated palaeo-records and improved quantitative reconstruction are required to provide quantitative insights into the processes of climatic changes, and their links to the EAM.

The goal of this paper is threefold. First we explore the temporal variability of a record located in a sensitive region at the northern edge of the EAM using a multiproxy approach. Second we explore the spatial variability of the Chinese climate at $6 \mathrm{ka} \mathrm{BP}$, when EAM is assumed to be the strongest. Third we illustrate a new methodology of climate reconstruction based on vegetation model inversion.

The temporal study is based on a core sampled in Lake Bayanchagan (Inner Mongolia) (Jiang et al., 2006) (Fig. 1). This region is particularly sensitive to climate variations as it is located at the edge of the present EAM. Their results suggest that this region was dominated by steppe vegetation throughout the Holocene, except for the period 9200 to $6700 \mathrm{yr} \mathrm{BP}$, when forest patches were relatively common. This period can then be correlated to enhanced EAM. But these findings need to be confirmed by a multiproxy analysis. We will synthesise in the first part of this paper an statistical approach based, in addition to pollen, on isotopic data and concentration of a green algae species (Jiang et al., 2008 ${ }^{1}$ ).

\footnotetext{
${ }^{1}$ Jiang, W., Guiot, J., Wu, H., Chu, G., Yuan, B., Hatté, C., and Guo, Z.: Reconstruction of Holocene summer monsoon history using $\mathrm{d} 18 \mathrm{O}$ of carbonate, Pediastrum and pollen records from lake
}

This study will focus on the timing of this enhanced EAM period.

This approach based on detailed time series in a sensitive region will be completed by a spatial analysis based also on pollen data but done with the newest tools involving a process model able to relate vegetation and climatic variations (Luo et al., 2008 ${ }^{2}$ ). The strong feature of this approach is to be able to take into account the large differences existing between present and mid-Holocene conditions as (i) climate seasonality, possibly resulting in lack of modern analogues, or (ii) atmospheric $\mathrm{CO}_{2}$ close to pre-industrial concentration but significantly lower than the present one. This spatial analysis will be first replaced in the context of previously published data syntheses at the sub-continental scale.

\section{Data syntheses}

An interesting story has been depicted by Ren and Beug (2002) in the northern half of China (north of Yangtze river) for the whole Holocene. Forests generally expanded in

sediments in northern China, Global Planet. Change, submitted, 2008.

${ }^{2}$ Luo, Y., Wu, H., Jiang, W., Guiot, J., and Sun, X.: Climatic changes in China at the Last Glacial Maximum and mid-Holocene: reconstruction from pollen data using inverse vegetation modelling, in preparation, 2008. 
the early Holocene times, reaching their maximum at 6 or $4 \mathrm{kaBP}$, with a maximum in Central China, and then regressed during the late Holocene. An exception was found for northeast China where the maximum development of forest occurred during the last 4000 or 2000 years. They concluded that, if the EAM enhancement seems to be responsible of the forest expansion at the beginning of the Holocene, disturbance by human activities may be responsible of the forest decline after $6 \mathrm{ka} \mathrm{BP}$.

This picture was completed by the study of $\mathrm{Yu}$ et al. (1998) who analysed the vegetation variations at the biome level for the whole China, but restricted at the $6 \mathrm{kaBP}$ period. In eastern China at $6 \mathrm{ka} \mathrm{BP}$, forest shifted northwards, with broadleaved evergreen forest extended about $300 \mathrm{~km}$ and temperate deciduous forest about $500-600 \mathrm{~km}$ beyond their present northern limit. In northwestern China, the area of desert and steppe vegetation was reduced as compared to present. They concluded that these shifts were likely a response to enhanced Asian monsoon.

Lake levels data are less susceptible to be influenced by human disturbances. Yu et al. (2003) proposed a story of the lake levels since the Last Glacial Maximum (LGM, about $21 \mathrm{kaBP}$ ). This compilation showed LGM conditions much drier than today in eastern China but somewhat wetter in western China. These east-west differential patterns of climate conditions were completely different from the modern dry-wet conditions with a north-south opposition. During the Holocene, at the mid-Holocene, both regions were wetter than present. Modern dry conditions returned after 5-4 ka BP depending on the region. Then if humans played a role in the forest decline in the Late Holocene, they simply accentuated a climatic trend. Atmopheric general circulation models (AGCM) coupled with land surface process model showed that the dry conditions in eastern China resulted from less summer precipitation due to the Pacific Subtropical High occupying eastern China and the decline in the summer monsoon.

More at north, in Mongolia, Tarasov et al. (1999) reconstructed, from pollen, warmer and wetter at $6 \mathrm{ka} \mathrm{BP}$ conditions for the northern part of the country, in agreement with higher lake levels. In the central part of the country, warmer and drier conditions prevailed (inferred from pollen, no lake data being available). But these dry conditions are likely due to more evapotranspiration and not necessarily to less precipitation.

\section{A multi-proxy technique to reconstruct climate time variability in Inner Mongolia}

The syntheses presented above are based either on pollen data or lake lavels data. A multi-proxy approach is now presented to reinforce and precise these results (Jiang et al., $\left.2008^{1}\right)$. It is based on a record taken from Lake Bayanchagan (115.21 ${ }^{\circ} \mathrm{E}, 41.65^{\circ} \mathrm{N}, 1355 \mathrm{~m}$ a.s.1, Fig. 1) in Inner Mongolia, which is today almost completely dry due to anthropogenic water use, with only small patches of shallow water maintained by summer rain. It is situated at the current northern edge of the summer monsoon. The mean annual temperature in the area is about $3^{\circ} \mathrm{C}$, and total annual precipitation is $300-400 \mathrm{~mm}$. About $70 \%$ of the precipitation occurs during the summer. The data used are pollen taxa counted for 90 pollen assemblages and 2066 surface samples. The taxa are grouped into 17 plant functional types (e.g. boreal evergreen conifers, steppics, grass, temperate summergreen trees, etc.) to reduce the number of variables and also to consider together taxa which respond in the same way to climatic variations. These plant functional types (PFT) are used to reconstruct climate by the modern analogue method (PFT-MAT) proposed by Davis et al. (2003) and Jiang et al. (2006). The climatic variables considered are the temperature of the coldest month (MTCO), the temperature of the warmest month (MTWA), the annual precipitation (MAP), the ratio actual evapotranspiration over potential evapotranspiration $(\alpha)$. These variables are calculated by linear interpolation from meteorological stations (Jiang et al., 2006) and $\alpha$ is obtained from monthly temperature, precipitation and sunshine variables using the Priestley-Taylor equation (Prentice et al., 1992).

To these proxies, are added total pollen concentrations, Pediastrum (a green algae that indicate shallow lake water) concentrations and $\delta^{18} \mathrm{O}$ of authigenic carbonate, i.e. on the $<40 \mu \mathrm{m}$ fraction (Jiang et al., 2008 ${ }^{1}$ ). These three proxies show a similar general pattern during the Holocene (Fig. 2a). Before 11000 cal yr BP, there is no Pediastrum in the lake. Pollen concentrations are lower than $2 \times 10^{5}$ grains $/ \mathrm{ml}$. All $\delta^{18} \mathrm{O}$ values of authigenic carbonate are between -3 and $-1 \%$ VPDB. Similar values are found after $5 \mathrm{ka} \mathrm{BP}$ and in between, there is high concentrations of pollen and Pediastrum and low $\delta^{18} \mathrm{O}$ values. As Jiang et al. (2008) ${ }^{1}$ have shown that these three variables are controlled by balance between precipitation and evaporation, they can be synthetized a common signal, given here by their first principal component (Fig. 2c).

Jiang et al. (2008) ${ }^{1}$ have used PFT-MAT constrained by the first principal component PC1 (Fig. 2c) as an indicator of $\alpha$, a variable directly related to the water stress. This constrained analysis has already been proposed with different proxies by Seret et al. (1992); Guiot et al. (1993); Cheddadi et al. (1996); Magny et al. (2001). For each fossil pollen spectrum, analogues were selected from the modern pollen spectra dataset subject to a broad consistency requirement according to $\alpha$ values. If we note the difference $\delta \alpha$ between $\alpha$ of the analogue and the modern $\alpha_{o}$ at the lake (56\%), only the analogues $\mathrm{i}$ with a $\delta \alpha_{i}$ compatible with PC1 at time $t$, denoted $C_{t}$, were retained. This compatibility is defined as follows: 


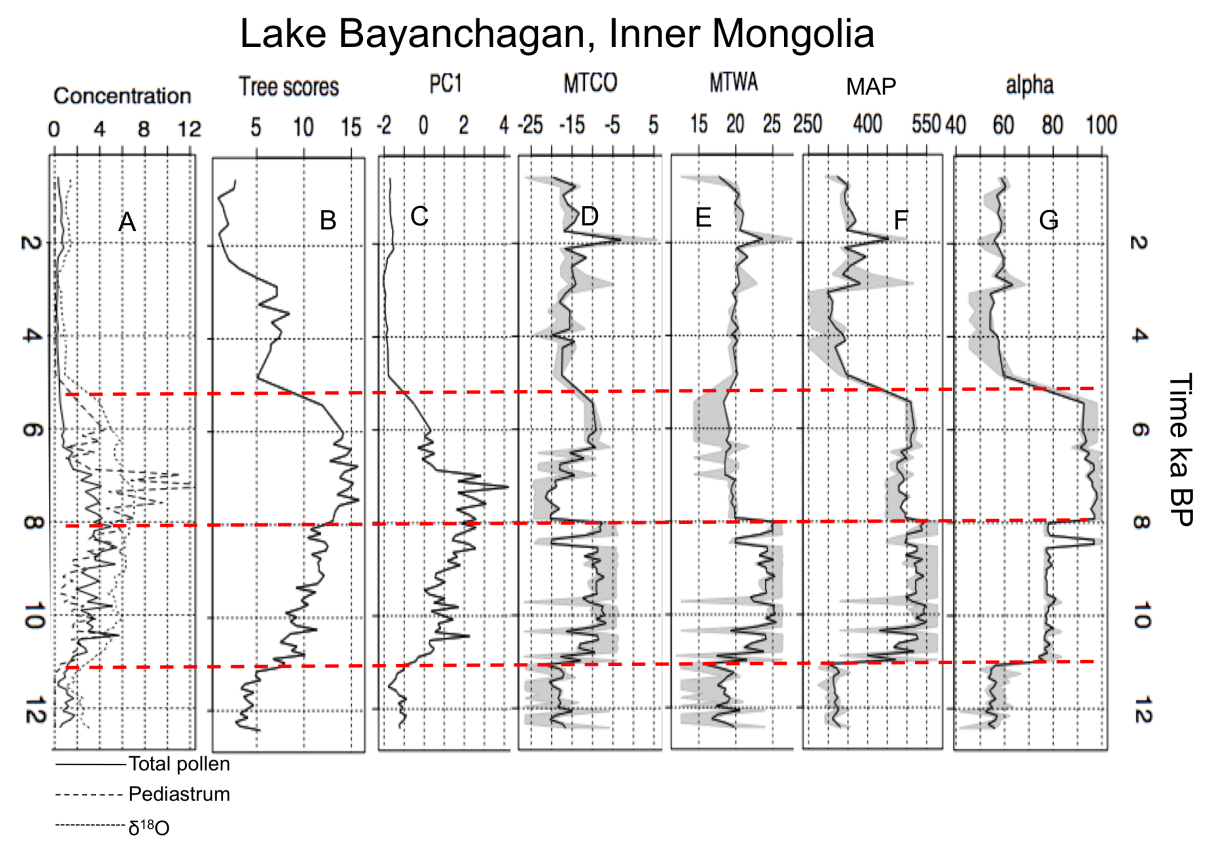

Fig. 2. Comparison of a few proxies ans the climatic reconstructions in Lake Bayanchagan (Inner Mongolia, China). (A) total pollen

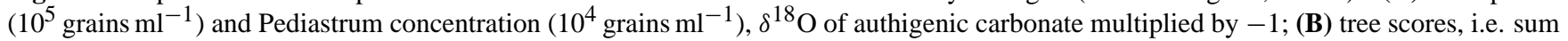
of the square root of the arboreal taxa percentages; (C) first principal component of the three proxies of (A); (D) mean temperature of the coldest month reconstruction; (E) mean temperature of the warmest month reconstruction; (F) total annual precipitation; (G) $\alpha$, the ratio between actual and equilibrium evapotranspiration. The climate reconstructions are represented with the uncertainties, given by the range of the analogues. After Jiang et al. (2008) ${ }^{1}$.

$$
\begin{array}{r}
C_{t}>2 \text { and } \delta \alpha_{i}>10 \% \\
C_{t}<-2 \text { and } \delta \alpha_{i}<-10 \% \\
-2 \leqslant C_{t} \leqslant 2 \text { and }-10 \% \leqslant \delta \alpha_{i} \leqslant 10 \%
\end{array}
$$

Figure 2 show the results obtained for the Lake Bayanchagan core: the reconstructed climatic variables are compared with the constraint PC1 and the scores of the arboreal pollen taxa (Fig. 2b). This enables one to question the direct relationship often proposed between an increase in tree components of pollen assemblages and a warmer and wetter climate (Shi et al., 1993; Liu et al., 2002; Xiao et al., 2004). So, the highest tree scores of trees during the Holocene in Lake Bayanchagan occurred between 8000 and 5500 cal yr BP (Fig. 2b). However, the peak period of trees was not in phase with the warmest and wettest climate reconstructed between 11000 and 8000 cal yr BP (Fig. 2d-f), suggesting that a single climatic variable is not the triggering factor. In contrast, variations in tree components and $\alpha$ were consistent (Figs. 2b and g). $\alpha$ is an integrated measure of annual amount of growth-limiting drought stress on plants related to both temperature and precipitation, and is one of primary factors influencing vegetation distributions (Prentice et al., 1992). The similarity in tree components and $\alpha$ variations inferred from our study indicates that it is also the main controlling factor for growth of trees over the Holocene in Inner Mongolia. $\alpha$ does not reach its maximum before $8 \mathrm{ka} \mathrm{BP}$ even if MAP is maximum because evaporation is too strong. The water stress is minimum only when temperature has decreased by a few degrees. The most favourable period for forest development is then between $8 \mathrm{ka}$ and $5 \mathrm{ka} \mathrm{BP}$.

The MAP record during the Holocene at Lake Bayanchagan is similar to $\delta^{18} \mathrm{O}$ records of stalagmite calcite from Dongge Cave and Shanbao Cave (Fig. 1) in EAM regions (Dykoski et al., 2005; Shao et al., 2006). Shifts in $\delta^{18} \mathrm{O}$ values of the stalagmite from the cave largely reflect changes in $\delta^{18} \mathrm{O}$ values of meteoric precipitation at the site, which in turn relates to changes in the amount of precipitation. The $\delta^{18} \mathrm{O}$ results show that monsoon precipitation increased dramatically at the start of the Holocene ( $\sim 11500$ cal yr BP) and remained high for $\sim 6000$ cal yr BP (Dykoski et al., 2005). This timing is consistent with other paleoclimatic records in EAM regions (Zhou et al., 2004, 2005). Both the Lake Bayanchagan data and stalagmite $\delta^{18} \mathrm{O}$ records from Dongge Cave and Shanbao Cave show the termination of monsoon precipitation maximum was abrupt between 6000 and 4400 cal yr BP.

The second warm and humid period at Lake Bayanchagan centered at $6000 \mathrm{cal} \mathrm{yr}$ BP. This event was characterized by increased MTCO, decreased MTWA and high precipitation 
(Fig. 2d-f). These results agree with a marked increase in winter temperatures across eastern China at $6000 \mathrm{cal} \mathrm{yr} \mathrm{BP}$ estimated from pollen data (Yu et al., 1998) and simulated by climatic model (Yu et al., 2003). The short-term cold event between 8500 and 8300 cal yr BP was characterized by decreases in both winter and summer temperature (Fig. 2d-f). Even if such event has been recorded in several places and in particular in the GRIP and GISP2 records (Alley et al., 1997; Rohling and Palike, 2005), it cannot be considered as significant in our reconstruction, as several such peaks are reconstructed during the Holocene.

\section{A inverse modelling technique to reconstruct climate spatial variability in China}

Multi-proxy approach is a way to produce robust paleoclimatic information but, as it is based on modern data using a statistical approach, it does not solve all the problems. The reconstruction methods are built upon the assumption that plant-climate interactions remain the same through time, and implicitly assume that these interactions are independent of changes in atmospheric $\mathrm{CO}_{2}$. This assumption may lead to a considerable bias, as polar ice core records show that the atmospheric $\mathrm{CO}_{2}$ concentration has fluctuated significantly over the past (EPICA, 2004). At the same time, a number of physiological and palaeoecological studies (Farquhar, 1997; Jolly and Haxeltine, 1997; Cowling and Sykes, 1999) have shown that plant-climate interactions are sensitive to atmospheric $\mathrm{CO}_{2}$ concentration. Therefore, the use of mechanistic vegetation models has been proposed to deal with these problems (Guiot et al., 2000). Wu et al. (2007) have improved the approach based on the BIOME4 model to provide better spatial and quantitative climate estimates from pollen records and correct for $\mathrm{CO}_{2}$ bias to pollen-based climate reconstructions in Eurasia and Africa. The same method is quickly presented here for Eastern Asian data.

\subsection{Data and method}

The pollen data used have been compiled by the BIOME6000 project (Prentice and Jolly, 2000) for three key periods: $0 \mathrm{k}$, $6 \mathrm{k}$ and $21 \mathrm{ka} \mathrm{BP}$ to classify pollen assemblages into a set of vegetation types. For the study described here, a subset containing 601 sample sites for $0 \mathrm{ka} \mathrm{BP}$ and 116 sites for $6 \mathrm{ka} \mathrm{BP}$ from China and Mongolia were used (MCPD, 2000, 2001; Tarasov et al., 1998). The selection of the $6 \mathrm{ka} \mathrm{BP}$ samples is based following the BIOME6000 convention. Among them, 84 sites have a good age control, i.e. either with at least two dates encompassing $6 \mathrm{ka} \mathrm{BP}$ at less than than 2000 years distance.

BIOME4 is a physiological-process global vegetation model, with a photosynthesis scheme that simulates the response of plants to changed atmospheric $\mathrm{CO}_{2}$ and by accounting for the effects of $\mathrm{CO}_{2}$ on net assimilation, stomatal conductance, leaf area index and ecosystem water balance. It is driven by monthly temperature, precipitation, sunshine, by absolute minimum temperature, $\mathrm{CO}_{2}$ concentration and soil texture. The principle of the model inversion is to estimate the input to BIOME4, the monthly climate, given that we know some information related to the output of the model, biome scores derived from pollen in our case (Prentice et al., 1996). This inversion, which uses a Monte-Carlo-MarkovChain algorithm to explore possible combinations of climate parameters, allows an assessment of the probability of different anomalies, and therefore the investigation of different scenarios which may result in similar vegetation pattern. The procedure is described in Wu et al. (2007). As Guiot et al. (2000), they showed that several solutions were possible for the LGM climate in Western Europe where a mixture of steppes and tundra existed. As these biomes have no clear analogues today, reconstructions based on statistical methods will tend to choose the least poor match or fail to find a real match. With the inverse modelling, Wu et al. (2007) showed that a climate significantly warmer than inferred with modern $\mathrm{CO}_{2}$ levels was the most probable. The overestimation of MTCO anomalies was about $10^{\circ} \mathrm{C}$. Moreover uncertainties were also underestimated with the statistical methods.

\subsection{Validation}

We present here an analysis of Chinese mid-Holocene data (Luo et al., $2008^{2}$ ). In a first step, the ability of this inversion scheme to reproduce the modern climate of China is evaluated, using the 601 modern spectra available. The statistical squared correlations $\left(R^{2}\right)$ between actual and reconstructed climate variables at the sample sites are presented in Fig. 3. These $R^{2}$ are very large, generally above 0.67 , except for MTWA which then does not appear to be a key factor to explain the modern vegetation distribution in China. The straight line between estimates and observations is expected to have an intercept of 0 and a slope of 1 . The slope is slightly biased for MTWA, GDD and MAP. The intercepts are biased for MTCO, MTWA and MAT, showing a tendency to overestimate the cold climates. There is also large error in estimating MAP and $\alpha$ in cold desert sites of the Tibet Plateau, where $\alpha$ below $60 \%$ are frequently estimated below $20 \%$, i.e. values typical of warmer deserts.

\subsection{The $6000 \mathrm{yr}$ BP climate}

For the $6 \mathrm{ka} \mathrm{BP}$ period, the atmopsheric $\mathrm{CO}_{2}$ concentration is set to 270 ppmv (EPICA, 2004). The results (MAP, MAT, $\alpha$ ) are presented as maps of anomalies versus present climate (Fig. 4). Large circles indicate significant differences from the modern values. The results show that, in most of the sites at $6 \mathrm{kaBP}$, the changes in precipitation and $\alpha$ were significantly different from modern values, while most of temperature changes are not. This is due to the larger uncertainty on the reconstructed temperature, which indicates a larger 


\section{Validation of the inverse modelling method on modern samples}
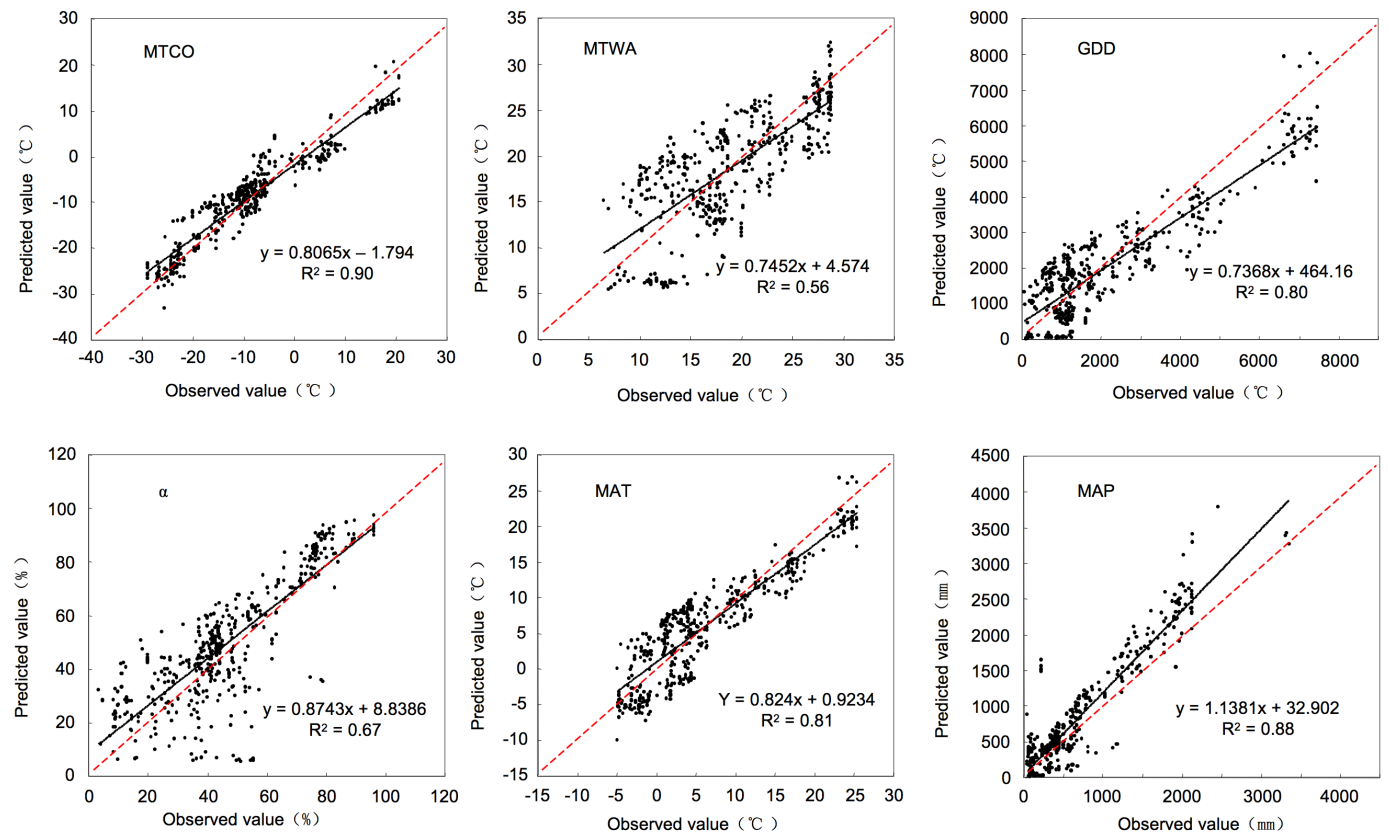

Fig. 3. Validation of the inverse BIOME4 modelling on the 601 samples of the modern database of China and Eurasia. The six reconstructed variables are compared to the observed climate: $\mathrm{MTCO}$ (mean temperature of the coldest month reconstruction), present value $=-20^{\circ} \mathrm{C}$, (MTWA) mean temperature of the warmest month reconstruction, present value $=17^{\circ} \mathrm{C},(\mathrm{GDD})$ growing degree days abve $5^{\circ} \mathrm{C}$, present value $=1500^{\circ}$ days, $(\alpha)$, the ratio between actual and equilibrium evapotranspiration, present value $=30 \%$, (MAT) mean annual temperature, present value $=3^{\circ} \mathrm{C}$, (MAP) total annual precipitation, present value $=350 \mathrm{~mm}$.

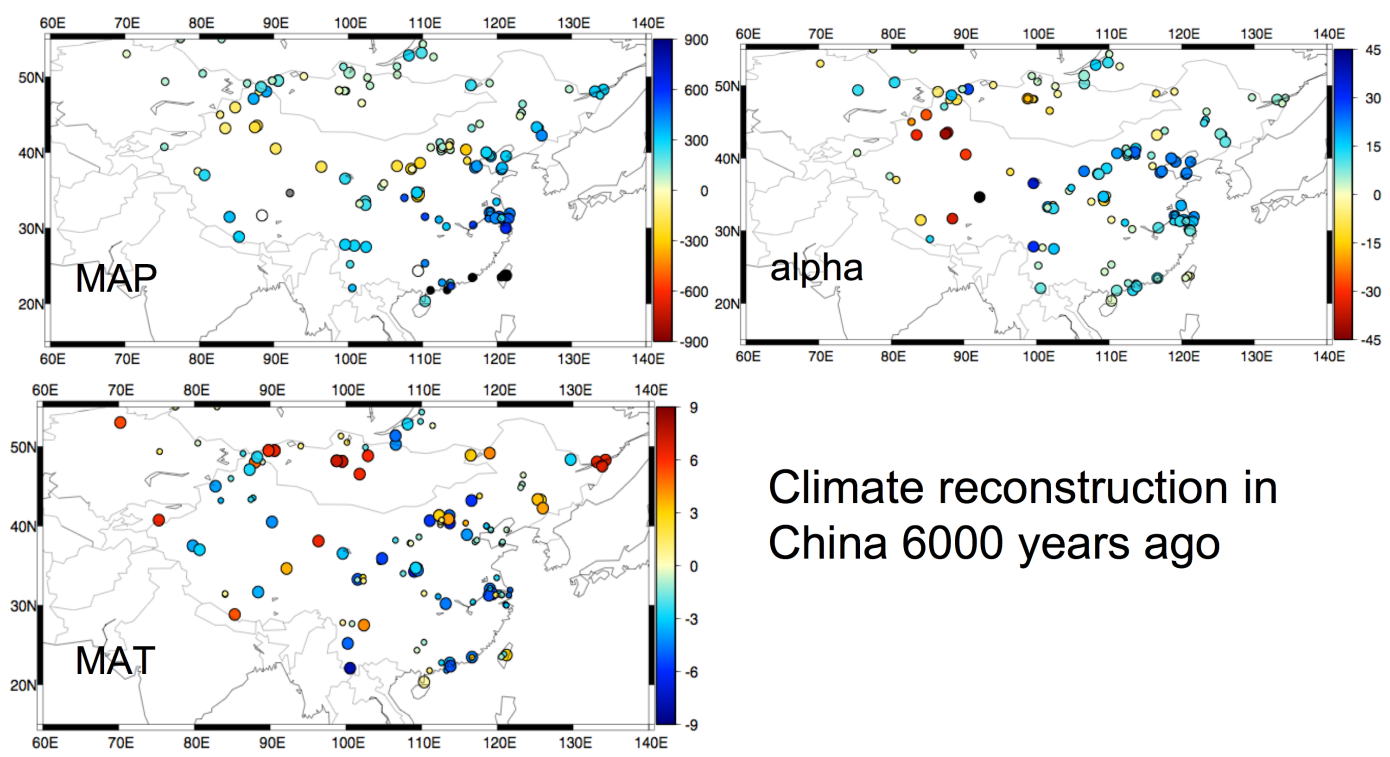

Fig. 4. Reconstruction of the climate in China 6000 years ago using inverse modelling method: $(\alpha)$, the ratio between actual and equilibrium evapotranspiration in \%, (MAT) mean annual temperature ${ }^{\circ} \mathrm{C}$, (MAP) total annual precipitation in mm. All the values are given in departures from present climate. Large circles indicate high significance levels (95\%), small circles indicate no significance. 
tolerance range of the vegetation to thermal variables while hydrological variables were more limiting factors. Annual temperature were generally lower than present one in southern China, but a significant warming was found over Mongolia, and a slight warming in northeast China.

Hydrological variables have a much more coherent distribution. MAP was generally higher than today in southern, northeast China, and northern Mongolia, but lower or similar to today in northwest China and north China. $\alpha$ was considerably higher than today in north China, and slightly higher than present in northeast China. In contrast, drier conditions are shown in northwest China and Mongolia.

Lake Bayanchagan is situated in a zone where most of the sites had a positive anomaly of MAP whereas a few ones had a negative one. This is broadly consistent with the reconstruction of Fig. 2e where MAP was found $200 \mathrm{~mm}$ higher than at present. The anomaly of $\alpha$ for this zone is significantly positive, between +15 and $30 \%$ in agreement with Fig. 2f where $\alpha$ was found 30\% higher than at present. For these two variables, Lake Bayanchagan reconstruction provide values at the upper limit of the inverse modelling. MAT appears also higher than at present, in good agreement with the reconstruction of Fig. 2c-d. The reconstructions based on the inverse modelling are then approximately consistent with the Lake Bayanchagan, at least for the majority of surrounding sites, but the multiproxy statistical approach infers values at the wetter limit of the inverse modelling. When compared to Tarasov et al. (1999), Fig. 4 shows also wetter and warmer conditions on northern Mongolia and warmer and drier conditions In the central part of the country.

\section{Discussion}

We have explored the temporal variability of the Lake Bayanchagan record located in a sensitive region at the northern edge of the EAM. The use of a multiproxy approach coupled with robust statistics have enlightened the complexity of the climatic signal. A key problem in this respect is the timing of the monsoon enhancement. Monsoon increase is translated in terms of increased precipitation. Then the period of maximum EAM occurred between 10.5 and $8 \mathrm{kaBP}$. A too rapid interpretation of the tree pollen curve should put this maximum between 8 and $5 \mathrm{ka} \mathrm{BP}$. It is clear that precipitation was higher than at present time across the two periods. But, extension of forest depends as well of temperature than precipitation, and our quantitative evaluation of several proxies show a more complex behaviour than Dongge and Shanbao cave series. This may also be due to spatial differences, the caves being located at much more lower latitudes than the lake (Fig. 1). This is confirmed by the post- $5 \mathrm{ka} \mathrm{BP}$ decrease in the lake records where precipitation returns to the LateGlacial level, while in the cave record, $\delta^{18} \mathrm{O}$ remains at an intermediate level. This might be explained by a rapid northward advance of the northern limit of the summer monsoon at
$11.5 \mathrm{ka} \mathrm{BP}$ (beyond $41^{\circ} \mathrm{N}$ ) followed by a slow retreat, falling back south of Lake Bayanchangan by $5 \mathrm{ka}$, while the caves, being further south, remain under the monsoon influence. This illustrates well that Lake Bayanchagan, at the northern edge of the EAM zone, is a sensitive record of the monsoon signal.

A second implication concerns the physical mechanisms. EAM enhancement is related to summer radiation which is maximum at $9 \mathrm{ka} \mathrm{BP}$ and rapidly decreases to be at $6 \mathrm{ka} \mathrm{BP}$ on the same level than at $12 \mathrm{ka} \mathrm{BP}$ (Berger, 1978; An, 2000). When a large number of climate model simulations are compared (Braconnot et al., 2002), a robust feature is that the extension of the monsoon is related to the Eurasian continent warming. This might explain why the $8-5 \mathrm{kaBP}$ period is characterised by a slight decrease of EAM accompanyed by a decrease of temperature more marked in this northern lake than in lower latitudes. Maximum temperature of the warmest month falls by $5^{\circ} \mathrm{C}$ at $8 \mathrm{kaBP}$ (but keep a level above the present one), which shows a mitigation of the impact on vegetation of the monsoon weakening by a sharp reduction of the evapotranspiration.

The analysis of the spatial variability of the Chinese climate at $6 \mathrm{kaBP}$ - even if the $6 \mathrm{ka}$ period is not the period of maximum monsoon enhancement - permits to replace the timing found for Lake Bayanchagan in a larger context. Figure 3 shows that some sites in the region of this lake have already a reduced precipitation, while $\alpha$, which represents the water availability for vegetation, is still higher than at present. This is still a period favourable to maintain forest, even with a precipitation reduction. Annual temperature distribution shows higher values than at present time in northern China, but lower in southern and central China where monsoon had still a higher influence. This illustrates well the fact that northern China was more at that time under the influence of the Eurasian continent while the rest of China was under still the influence of the ocean through the Pacific Subtropical High.

A last point is the use of a new methodology of climate reconstruction based on vegetation model inversion. As already mentionned, this mechanistic model offers the possibility to escape from too constraining modern conditions as high atmospheric $\mathrm{CO}_{2}$ concentrations or a climate seasonnality different from modern one (in relation with insolation). The climatic maps obtained for $6 \mathrm{ka}$ BP confirmed previous results based on modern analogues, likely because $\mathrm{CO}_{2}$ concentration is sufficiently high. Wu et al. (2007) have shown that, for the Last Glacial Maximum conditions, biases are introduced by the fact that $\mathrm{CO}_{2}$ is sufficiently low to have limited vegetation productivity in a comparable amplitude than climate change. 


\section{Conclusions}

Various syntheses have been done on Chinese paleodata using various methods. All converges to reconstruct intensification of EAM in China at $6 \mathrm{ka} \mathrm{BP}$, especially on eastern part of China. Northern China cores indicate an intensified monsoon between 10 and $5 \mathrm{ka} \mathrm{BP}$. After $8 \mathrm{ka} \mathrm{BP}$, a cooler climate induced a less strong water stress, favouring the largest extend of the forest. This two-step division of mid-Holocene has been possible thanks to a multi-proxy approach enabling more robust inference. Nevertheless, all approach involving modern analogues has its own limit when extrapolation is done on periods with characteristics very different from the present reference period. Then the use of mechanistic models in an inverse mode enables one to control the effect of external variables, such as atmospheric $\mathrm{CO}_{2}$.

The results based on inverse modelling are coherent with the previous syntheses. They show that a pattern of higher precipitation is clear on eastern half of China. On western part of China, the situation is less contrasted with higher precipitation on southwest and lower on northweast. The eastern China situation is related to enhanced summer monsoon associated with the Pacific Subtropical High bringing warm and most marine air from the West Pacific Ocean to eastern China. The situation of southwestern China can be related to the Indian summer monsoon bringing most marine air from the Indian Ocean to southern Tibetan Plateau and southern China lowlands. Northwestern regions are sheltered from these monsoon changes by the Tibetan Plateau and are dominated by the Westerlies and Asian winter monsoon. Increased land-sea contrast due to higher summer insolation at mid-Holocene will then influence more strongly eastern China.

Acknowledgements. This research has been partly funded by a grant of the French Ministry of Research to two authors, the 5th PCRD EU project MOTIF (EVK2-CT-2002-00153), by the European Science Foundation, EUROCLIMATE/DECVEG and the French ANR PICC.

Edited by: Ryuji Tada

\section{References}

Alley, R. B., Mayewski, P. A., Sowers, T., Stuiver, M., Taylor, K. C., and Clark, P. U.: Holocene climatic instability: A prominent, widespread event 8200 yr ago, Geology, 25, 483-486, 1997.

An, C., Feng, Z.-D., and Barton, L.: Dry or humid? Mid-Holocene humidity changes in arid and semi-arid China, Quaternary Sci. Rev., 25, 351-361, 2006.

An, Z. S.: The history and variability of the East Asian paleomonsoon climate, Quaternary Sci. Rev., 19, 171-187, 2000.

Berger, A.: Long-term variations of caloric insolation resulting from the earth's orbital elements, Quaternary Res., 9, 139-167, 1978.
Braconnot, P., Loutre, M. F., Dong, B., Joussaume, S., and Valdes, P.: How the simulated change in monsoon at $6 \mathrm{ka} \mathrm{BP}$ is related to the simulation of the modern climate: results from the Paleoclimate Modeling Intercomparison Project, Clim. Dynam., 19, 107-121, 2002.

Cheddadi, R., Yu, G., Guiot, J., Harrison, S. P., and Prentice, I. C.: The climate of Europe 6000 years ago, Clim. Dynam., 13, 1-9, 1996.

Cowling, S. and Sykes, M.: Physiological significance of low atmospheric CO2 for plant-climate interactions, Quaternary Res., 52, 237-242, 1999.

Davis, B. A. S., Brewer, S., Stevenson, A. C., Guiot, J., and contributors: The temperature of Europe during the Holocene reconstructed from pollen data, Quaternary Sci. Rev., 22, 1701-1716, 2003.

Dykoski, C. A., Edwards, R. L., Cheng, H., Yuan, D. X., Cai, Y. J., Zhang, M. L., Lin, Y. S., Qing, J. M., An, Z. S., and Revenaugh, J.: A high-resolution, absolute-dated Holocene and deglacial Asian monsoon record from Dongge Cave, China, Earth Planet. Sci. Lett., 233, 71-86, 2005.

EPICA: Eight Glacial cycles from an Antarctic ice core, Nature, 429, 623-628, 2004.

Farquhar, G. D.: Carbon dioxide and vegetation, Science, 278, 1411-1411, 1997.

Guiot, J., Beaulieu de, J. L., Cheddadi, R., David, F., Ponel, P., and Reille, M.: The climate in Western Europe during the last Glacial/Interglacial cycle derived from pollen and insect remains, Palaeogeogr. Palaeocl., 103, 73-93, 1993.

Guiot, J., Torre, F., Jolly, D., Peyron, O., Boreux, J. J., and Cheddadi, R.: Inverse vegetation modeling by Monte Carlo sampling to reconstruct palaeoclimates under changed precipitation seasonality and $\mathrm{CO} 2$ conditions: application to glacial climate in Mediterranean region, Ecol. Model., 127, 119-140, 2000.

He, Y., Theakstone, W., Zhang, Z., Zhang, D., Yao, T., Chen, T., Shen, Y., and Pang, H.: Asynchronous Holocene climatic change across China, Quaternary Res., 61, 52-63, 2004.

Jiang, W., Guo, Z., Sun, X., Wu, H., Chu, G., Yuan, B., Hatté, C., and Guiot, J.: Reconstruction of climate and vegetation changes of Lake Bayanchagan (Inner Mongolia): Holocene variability of the East Asian monsoon, Quaternary Res., 65, 411-420, 2006.

Jolly, D. and Haxeltine, A.: Effect of low glacial atmospheric CO2 on tropical African montane vegetation, Science, 276, 786-788, 1997.

Joussaume, S. and Taylor, K.: Status of the PMIP, Proceedings of the First International AMIP Scientific Conference, WMO, Geneva, 425-430, 1995.

Liu, H. Y., Xu, L. H., and Cui, H. T.: Holocene history of desertification along the woodland-steppe border in northern China, Quaternary Res., 57, 259-270, 2002.

Magny, M., Guiot, J., and Schoellammer, P.: Quantitative reconstruction of Younger Dryas to mid-Holocene paleoclimates at Le Locle, Swiss Jura, using pollen and lake- level data, Quaternary Res., 56, 170-180, 2001.

MCPD (Members of China Quaternary Pollen Database): Pollenbased Biome Reconstruction at Middle Holocene (6 ka BP) and Last Glacial Maximum (18 ka BP) in China, J. Integr. Plant Biol., 42, 1201-1209, 2000.

MCPD (Members of China Quaternary Pollen Database): Simulation of China Biome Reconstruction Based on Pollen Data from 
Surface Sediment Samples. Journal of Integrative Plant Biology, J. Integr. Plant Biol., 43, 201-209, 2001.

Prentice, I. C. and Jolly, D.: Mid-Holocene and glacial-maximum vegetation geography of the northern continents and Africa, J. Biogeogr., 27(3), 507-519, 2000.

Prentice, I. C., Cramer, W., Harrison, S. P., Leemans, R., Monserud, R. A., and Solomon, A. M.: A global biome model based on plant physiology and dominance, soil properties and climate, J. Biogeogr., 19, 117-134, 1992.

Prentice, I. C., Guiot, J., Huntley, B., Jolly, D., and Cheddadi, R.: Reconstructing biomes from palaeoecological data: A general method and its application to European pollen data at 0 and $6 \mathrm{ka}$, Clim. Dynam., 12, 185-194, 1996.

Ren, G. Y. and Beug, H. J.: Mapping Holocene pollen data and vegetation of China, Quaternary Sci. Rev., 21, 1395-1422, 2002.

Rohling, E. J. and Palike, H.: Centennial-scale climate cooling with a sudden cold event around 8,200 years ago, Nature, 434, 975979, 2005

Seret, G., Guiot, J., Wansard, G., Beaulieu, J. L. d., and Reille, M.: Tentative Palaeoclimatic Reconstruction Linking Pollen and Sedimentology in La Grande Pile (Vosges, France), Quaternary Sci. Rev., 11, 425-430, 1992.

Shao, X., Wang, Y., Cheng, H., Kong, X., Wu, J., and Lawrence, E.: Long-term trend and abrupt events of the Holocene Asian monsoon inferred from a stalagmite $\delta 18^{O}$ record from Shennongjia in Central China, Chinese Sci. Bull., 51, 221-228, 2006.

Shi, Y. F., Kong, Z. Z., Wang, S. M., Tang, L. Y., Wang, F. B., Yao, T. D., Zhao, X. T., Zhang, P. Y., and Shi, S. H.: Mid-Holocene Climates and Environments in China, Global Planet. Change, 7, 219-233, 1993.

Tarasov, P. E., Webb, T. I., Andreev, A. A., Afanas' Eva, N. B., Berezina, N. A., Bezusko, L. G., Blyakharchuk, T. A., Bolikhovskaya, N. S., Cheddadi, R., Chernavskaya, M. M., Chernova, G. M., Dorofeyuk, N. I., Dirksen, V. G., Elina, G. A., Filimonova, L. V., Glebov, F. Z., Guiot, J., Gunova, V. S., Harrison, S. P., Jolly, D., Khomutova, V. I., Kvavadze, E. V., Osipova, I. M., Panova, N. K., Prentice, I. C., Saarse, L., Sevastyanov, D. V., Volkova, V. S., and Zernitskaya, V. P.: Present-day and midHolocene biomes reconstructed from pollen and plant macrofossil data from the former Soviet Union and Mongolia: Global change - BIOME 6000, J. Biogeogr., 25, 1029-1053, 1998.
Tarasov, P. E., Guiot, J., Cheddadi, R., Andreev, a. A., Bezusko, L. G., Blyakharchuk, T. A., Dorofeyuk, N. I., Filimonova, L. V., Volkova, V. S., and Zernitskaya, V. P.: Climate in Northern Eurasia 6000 Years Ago Reconstructed From Pollen Data, Earth Planet. Sci. Lett., 171, 635-645, 1999.

Wang, B., Clemens, S., and Liu, P.: Contrasting the Indian and East Asian monsoons: implications on geologic timescales, Mar. Geol., 201, 5-21, 2003.

Wei, K. and Gasse, F.: Oxygen Isotopes in Lacustrine Carbonates of West China Revisited: Implications for Post Glacial Changes in Summer Monsoon Circulation, Quaternary Sci. Rev., 18, 13151334, 1999.

Wu, H., Guiot, J., Brewer, S., and Guo, Z.: Climatic changes in Eurasia and Africa at the Last Glacial Maximum and midHolocene: reconstruction from pollen data using inverse vegetation modelling, Clim. Dynam., 29, 211-229, 2007.

Xiao, J. L., Xu, Q. H., Nakamura, T., Yang, X. L., Liang, W. D., and Inouchi, Y.: Holocene vegetation variation in the Daihai Lake region of north-central China: a direct indication of the Asian monsoon climatic history, Quaternary Sci. Rev., 23, 1669-1679, 2004.

Yu, G., Prentice, I. C., Harrison, S. P., and Sun, X. J.: Pollenbased biome reconstructions for China at 0 and 6000 years, J. Biogeogr., 25, 1055-1069, 1998.

Yu, G., Xue, B., Liu, J., and Chen, X.: LGM lake records from China and an analysis of climate dynamics using a modelling approach, Global Planet. Change, 38, 223-256, 2003.

Zhou, W. J., Yu, X. F., Jull, A. J. T., Burr, G., Xiao, J. Y., Lu, X. F., and Xian, F.: High-resolution evidence from southern China of an early Holocene optimum and a mid-Holocene dry event during the past 18,000 years, Quaternary Res., 62, 39-48, 2004.

Zhou, W. J., Xie, S. C., Meyers, P. A., and Zheng, Y. H.: Reconstruction of late glacial and Holocene climate evolution in southern China from geolipids and pollen in the Dingnan peat sequence, Org. Geochem., 36, 1272-1284, 2005. 